\title{
Indoor aerosol transport and deposition for various types of space heating
}

\author{
P. Podoliak, J. Katolicky \& M. Jicha \\ Brno University of Technology, Brno, Czech Republic
}

\begin{abstract}
Computational modelling of aerosol transport under various heating systems in a room was conducted with the goal to understand and evaluate a regional deposition and to assess an optimum position for air cleaning device. The room is equipped with a ventilation inlet integrated into one of the windows. The computational model room simulates a real room in an experimental house. Three heating systems are taken into account, namely radiators, floor heating and ceiling radiation panels. In total four cases are modelled for each heating system. Thermal diversity is simulated by varying the ventilation air flow and outdoor temperatures. Aerosol entering the room has the size of particles 1, 2.5 and $10 \mu \mathrm{m}$ diameters. The room is divided into several regions and sub-regions where the deposition is evaluated for individual aerosol sizes and outdoor and incoming air temperatures. Also the air velocity and temperature fields in the room are depicted to support the analysis of deposition patterns. The void fraction of the aerosol phase also shows the space distribution inside the room and provides us with an overall view of the aerosol transport. Based on the results of aerosol transport and deposition, an optimal location of an air cleaner can be selected.
\end{abstract}

Keywords: indoor aerosol, deposition, heating systems, CFD.

\section{Introduction}

Suspended particles belong to the most dangerous pollutants in both outdoor and indoor environments. As people spend the most of their lives in the indoor environment where they are exposed to suspended particles by breathing the ambient air, the issue of transport and deposition of particles indoors gets more and more attention [8]. Whilst this does not mean that indoor exposures produce 
more harmful health effects, the evidence is that indoor concentrations of many pollutants are often higher than those typically encountered outside [4].

The motion of particles in ventilated rooms is governed by the flow field, which determines their local and temporal concentrations and deposition. Numerous factors affect indoor particle concentrations including outdoor particles that penetrate indoors, indoor activities that generate particles, deposition of particles, and air exchange [2]. The influence of the geometry with furnishing of the room and thermal conditions are matter of course in order to generate the specific flow field. In the prediction of indoor particle concentration, it is necessary to take into consideration the particle size, wall texture and orientation [1].

The transport and deposition of aerosol particles was simulated by CFD in a model of a room using the Lagrangian multiphase flow in a steady state. Three types of space heating systems were simulated, namely: radiators, floor and ceiling heating. Different airflow patterns in the room were reached by changing the temperature of ventilation air and outdoor temperature. Four different temperatures of ventilation air in combination with outdoor temperature were simulated for each kind of heating. A heat load of thermal system was changed to ensure the thermal comfort in the room. The source of aerosol was situated to the inlet of the ventilation air. Three sizes of particles in diameters 1, 2.5 and $10 \mu \mathrm{m}$ were used with the characteristic concentrations of outdoor aerosol for the part of the city, where the experimental house is located. The effects of different heating systems on aerosol transport and deposition were investigated. The deposition was affected by gravitational settling, buoyancy caused by temperature gradient in the room, and also by the interaction between the discrete and continuous phase. The electrostatic or mechanical aspects of surfaces and re-suspension of particles were neglected. Particles were assumed to deposit when they reach the wall in the distance shorter than their radius in the near-wall region. Collected data were analysed to observe the interaction between the type of heating system and the amount of particles settled down on several surfaces of the room. The results of particles settled on surfaces were compared relatively in percentage.

\section{Methods}

The computational model for simulation of particles deposition was based on the real room situated in an experimental house in the Czech Republic on the campus of the Brno University of Technology in Brno. Main dimensions of model were $4.2 \times 6.3 \mathrm{~m}$ for the area of the floor and the room height was $2.7 \mathrm{~m}$. The main parts of the model are shown in figure 1 . The model of the room consists of nearly 450000 hexahedral cells. The size of the cells was changing down from $10 \mathrm{~cm}$ to $0.5 \mathrm{~cm}$. These fine cells were needed to achieve more accurate solution in the places where the gradients of values were high. It was primarily the area of the inlet, outlet, and radiators. Finer cells were also used in the near wall area. 
The task was simulated in a steady state. The Lagrangian approach was used to describe the two-phase flow of particles in the indoor air. For describing the turbulence behaviour of air, the k- $\varepsilon$ model with standard wall functions was used. Radiative heat transfer between internal surfaces was solved using the discrete ordinate method. For this transfer, the surface was divided into 1110 smaller surfaces, if possible, primarily as a square with the side length of $0.4 \mathrm{~m}$.

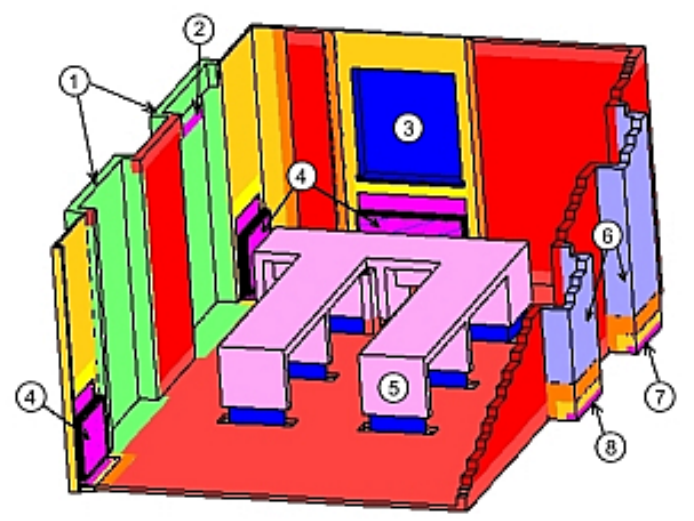

Figure 1: $\quad$ Model of the room with main parts: 1 - outer windows (French windows), 2 -inlet, 3 -window, 4 -radiators, 5 - furniture, 6 - inside doors, 7 and 8 - outlets.

Several boundary conditions, as needed, were used in the model. Wall boundary conditions were used for the floor, ceiling, surrounding walls, and windows. It was necessary to determine the thermal resistance of structures and also their radiative properties. Baffle boundary conditions were used for the radiators and furniture situated inside of the domain. The specific values used for each boundary are shown in table 1 .

Instead of thermal resistance parameters of material, the heat flux was set for radiators in case the radiator heating was turned on. In different cases of used heating systems it was necessary to set up the heat flux generated by the floor or ceiling as needed. The heat flux depended on the heat balance of the room and the ambient environment to reach the values of indoor air temperatures according to thermal comfort.

The change of temperatures resulted in a consequent change of heat loads in order to simulate several thermal situations. Owing to different temperature distribution, the air distribution in the room is also changed. As the characteristic values of the outdoor temperatures for the heating season the following values were assumed: the minimum $\left(-12^{\circ} \mathrm{C}\right)$ and the average $\left(3.6^{\circ} \mathrm{C}\right)$ outdoor temperatures given by national standard for the location of the house.

The ventilation of the room was realised by the inlet of the fresh outdoor air, which was built in the upper part of one of the windows. The fresh air was entering the direction perpendicular to the plane of the inlet with the velocity 
$0.126 \mathrm{~m} / \mathrm{s}$. This value corresponded to the air exchange rate $0.351 / \mathrm{h}$ for the volume of the simulated room. These ventilation conditions were chosen in terms of minimum hygienic requirements for an administrative kind of activity in the room. The temperature of the incoming air was the same as the outdoor temperature or the air was heated to the temperature $10^{\circ} \mathrm{C}$ and $20^{\circ} \mathrm{C}$ using preheating or recuperation in order to get several conditions indoor. The outlet was realised by the pressure boundary conditions at the bottom of both doors opposite the inlet. Four different thermal situations were simulated for three different types of space heating systems. Values of the specific heat flux for simulated temperature conditions and the heating area for each simulation are in table 2 .

Table 1: $\quad$ The values of thermal parameters and radiation properties.

\begin{tabular}{|l|l|l|l|l|}
\hline & $\begin{array}{l}\text { thermal resistance } \\
{\left[\mathrm{m}^{2} \mathrm{~K} / \mathrm{W}\right]}\end{array}$ & emissivity & reflectance & transmittance \\
\hline wall to indoor & 3.484 & 0.91 & 0.09 & 0.00 \\
\hline wall to outdoor & 6.71 & 0.91 & 0.09 & 0.00 \\
\hline indoor doors & 0.48 & 0.91 & 0.09 & 0.00 \\
\hline french windows & 0.953 & 0.84 & 0.08 & 0.08 \\
\hline ceiling & 3.47 & 0.91 & 0.09 & 0.00 \\
\hline floor & 7.186 & 0.91 & 0.09 & 0.00 \\
\hline window & 0.953 & 0.84 & 0.08 & 0.08 \\
\hline radiators & 0.0005 & 0.91 & 0.09 & 0.00 \\
\hline furniture & 0.02 & 0.91 & 0.09 & 0.00 \\
\hline
\end{tabular}

As for aerosol, the only source was the outdoor air coming into the room through ventilation. Under normal ventilation ratios of indoor to outdoor, particle number and mass are very closely to one [5]. Concentration of aerosol was taken from previous measurements of several concentrations of aerosol size classes in the streets of the city close the experimental house. We have chosen the average values of dust concentration in wintertime from the spectrum of size classes for three particle sizes with diameter 10, 2.5 and $1 \mu \mathrm{m}$ with concentrations 12,3 and $15 \mu \mathrm{g} / \mathrm{m}^{3}$ respectively. Also the average density of dust particles was taken $1500 \mathrm{~kg} / \mathrm{m}^{3}$.

The deposition of particles was reached using the subroutine for the behaviour of particles near the boundary condition. The point was that for the particle reaching the wall cell, zero velocity was assumed. After particles had settled down, they were removed numerically from the domain to avoid resuspension. This rule then enabled us to simplify and realize the deposition. Hence the effect of aerosol transport and deposition is very complex this simulation took into account only some aspects of this complex phenomenon. 
The interaction between discreet and continuous phase and the action of gravitation and buoyancy were taken into consideration but an electrostatic interaction or mechanical properties of surfaces were neglected.

Table 2: Values of heat flux with appropriate heating area for several simulations. $t_{\text {out }}$ - outdoor temperature, $t_{\text {vent }}$ - ventilation air temperature.

\begin{tabular}{|c|c|c|c|c|c|}
\hline \multirow{2}{*}{$\begin{array}{c}\text { used type of } \\
\text { heating }\end{array}$} & \multicolumn{3}{|c|}{ heat flux $\left[\mathrm{W} / \mathrm{m}^{2}\right]$ needed in the case of $\mathrm{t}_{\text {out }}$} & $\begin{array}{c}\text { area of } \\
\text { heating } \\
{\left[\mathrm{m}^{2}\right]}\end{array}$ \\
\cline { 2 - 5 } & $\begin{array}{c}3.6^{\circ} \mathrm{C} ; \\
3.6^{\circ} \mathrm{C}\end{array}$ & $\begin{array}{c}3.6^{\circ} \mathrm{C} ; \\
10^{\circ} \mathrm{C}\end{array}$ & $\begin{array}{c}3.6^{\circ} \mathrm{C} ; \\
20^{\circ} \mathrm{C}\end{array}$ & $\begin{array}{c}-12^{\circ} \mathrm{C} ; \\
-12^{\circ} \mathrm{C}\end{array}$ & \\
\hline radiator & 105.3 & 92.8 & 82.7 & 156.7 & 9 \\
\hline floor & 31.7 & 26.1 & 26.2 & 44.6 & 27.58 \\
\hline ceiling & 34.6 & 31.5 & 28.1 & 53.8 & 27.58 \\
\hline
\end{tabular}

\section{Results and discussion}

To carry out the comparison of different simulation cases, five planes of interest were defined. Because of the action of airflow, momentum is transmitted to aerosol particles, and the location of planes was chosen to capture the main aspects of forming the fields of air distribution. The cold air coming from the outside fell down below the inlet in contrast to the convective flow of hot air over the radiators. The inlet and radiators zones were the places where the velocities of air and the temperature gradients reached the highest values. Therefore the analysis of aerosol transport and deposition was also supported by calculation of both thermal and velocity fields.

The void fraction fields served for quantifying the contamination of the air. The most contaminated environment was in the case when the room was heated by the radiator, the outdoor temperature being $3.6^{\circ} \mathrm{C}$ and the ventilation air heated to $10^{\circ} \mathrm{C}$ while the least contaminated environment was simulated for the same thermal conditions but the ceiling heating was present. Qualitative pictures of particles transport and distribution showed the same. Figure 2 shows the cases of the same thermal conditions but different heating systems. The spatial view of the model and the dispersed aerosol in it brings about the most objective image of the indoor air contamination.

301 local regions were defined on all surfaces of the room to compute the deposition on each of them. The area of each region was approximately $0.8 \times 0.8 \mathrm{~m}^{2}$. These areas were joined together into sub-regions where the deposition was evaluated for individual aerosol sizes and outdoor and indoor temperatures. Sub-regions were based on the same area as boundary conditions were defined. The deposition analysis on each of them shows both the relative percentage of total amount of particles released into the domain and the surface flux in $\mu \mathrm{g} / \mathrm{m}^{2}$. 

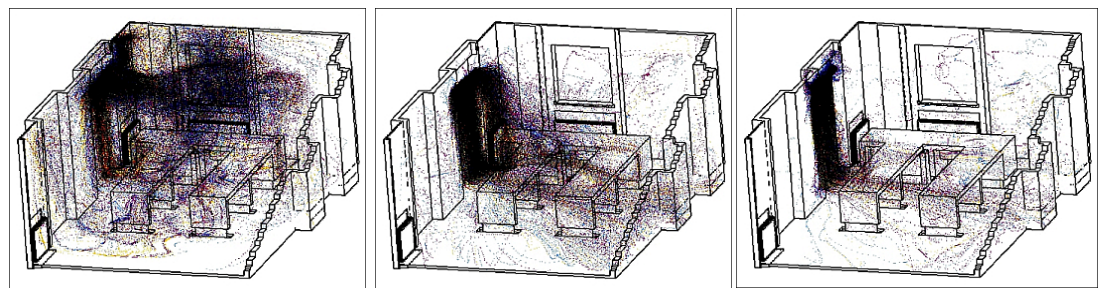

Figure 2: Spatial view of dispersed particles in the room for $t_{\text {out }}=3.6^{\circ} \mathrm{C}$, $\mathrm{t}_{\mathrm{vent}}=10^{\circ} \mathrm{C}$ in the following order: radiator, floor and ceiling heating system.

A large number of particles have settled down directly on the window under the inlet of air. This was caused by the fall of cold air down along the window and the wall; right after this air entered the room. This number of settled particles was between $63-83 \%$ in the case of ceiling heating, $29-71 \%$ for floor heating and $18-55 \%$ for radiator heating depended on the assigned thermal conditions. The amount of settled particles in that area was getting lower with the inlet of warmer ventilation air and was almost uniform for each size of particles with the exception of radiator heating. The deposition of $1 \mu \mathrm{m}$ and $2.5 \mu \mathrm{m}$ particles was lower (from 13 up to $26,7 \%$ ) than the deposition of $10 \mu \mathrm{m}$ particles on the window under the inlet. The effects of gravitational settling on $10 \mu \mathrm{m}$ particles could be the cause why the deposition of them is higher while for the smaller particles it is easier to be yielded to convective fluxes. The same result about the deposition and gravitational settling was confirmed by Zhao [8]. Holmberg and $\mathrm{Li}$ [3] showed the difference between the amount of particles settled on the floor and on the walls for particles of size 2.5 and $4.5 \mu \mathrm{m}$ too. The comparison can only be considered as an example.

Surface mass flux was always the highest in the outlet and on the window under the inlet. The highest values depend on the smallest area of the outlet and the high concentration of particles near the inlet area. The values of the surface mass flux were for the outlet in the order of $0.1 \mu \mathrm{g} / \mathrm{m}^{2} \mathrm{~s}$ and for the window under the inlet in the range between 0.001 and $0.01 \mu \mathrm{g} / \mathrm{m}^{2} \mathrm{~s}$. The flux on other surfaces varied from zero to order of $0.001 \mu \mathrm{g} / \mathrm{m}^{2}$ s. According to the highest mass flux which is independent of the surface, we could find the places for the air cleaner with highest efficiency of cleaning.

Due to minimal dispersion of the particles for the case of ceiling heating, the main area of the deposition was affected by the range of ventilation air. Therefore, next to the deposition under the inlet, particles were settled on the floor; nearly all the remaining particles settled there in the amount of $8-30 \%$. The difference between the particles settled on the floor of larger size $10 \mu \mathrm{m}$ and smaller particles of $1 \mu \mathrm{m}$ and $2.5 \mu \mathrm{m}$ was $10 \%$ in the case of the ventilation with the air of temperature $20^{\circ} \mathrm{C}$. The warmer was the ventilation air entering the room, the higher was the distance reached and more particles of the size $1 \mu \mathrm{m}$ and $2.5 \mu \mathrm{m}$ were noticed in the area of the outlet situated opposite to the inlet in 
concentrations up to $8 \%$. It corresponds to the lower deposition on the floor. Other surfaces did not gain more than $2 \%$ of particles of each particle size.

Floor heating was similar in deposition to ceiling heating. The deposition on the window under the inlet reached lower values. The values for the inlet area have already been mentioned. As for the floor values, these values were between $13-29 \%$. $10 \mu \mathrm{m}$ particles reached the highest values; these values were nearly constant for all thermal conditions. The velocities of the air seem be higher in that case than in the case of ceiling heating. Due to radiative heat transfer, more surfaces provide a better view on the heated surface, (e.g. the bottom of furniture and radiators), earn more heat and therefore are warmer. The same behaviour of particles was observed with ceiling heating. Also the rule that the warmer was the air entering the room, the higher was dispersion of particles in the air, took place. It could be shown on the balance of the deposition on the side of the room where the inlet is situated. The deposition on the wall increased while the deposition on the window under the inlet area decreased. It proceeded nearly proportionally considering the higher deposition on the furniture, outlet and slightly also on the other surfaces. The deposition on the furniture varied from 4 to $13 \%$ and at the outlet from $2 \%$ to $5 \%$ for $10 \mu \mathrm{m}$ particles and up to $11 \%$ for the smaller particles. The deposition reached the values only between $2-4 \%$ on the side wall where the outlet was situated. The deposition on the other surfaces was more significant than in the case of ceiling heating where the deposition was mainly realised on the three of ten analysed surfaces. Therefore the values of these appropriate surfaces are lower in the case of floor heating.

The deposition on the ceiling was minimal in both of used heating systems taking into account the large area of ceiling. Mainly the particles of the size $1 \mu \mathrm{m}$ were depositing. The highest values they reached were only $2.5 \%$ in the case of floor heating and $1 \%$ in the case of ceiling heating when the temperature of the ventilation air was $20^{\circ} \mathrm{C}$. The highest deposition on the ceiling was in the case of radiator heating. Hot air rising over the radiators raises the particles to the upper part of the room as we can also see from the transport of the particles. The velocities of the air in the area over radiators increased 3 times by turning the radiator heating on. The deposition of the particles on the ceiling was connected with the intensity of heating. The deposition of fine particles was $28 \%$ while $10 \mu \mathrm{m}$ particles reached $20 \%$ for the case of the highest heat flux. Values of deposition varied down to $14 \%$ for fine particles and to $7 \%$ for $10 \mu \mathrm{m}$ particles for the case of the lowest heat flux. The difference between these values was nearly uniform.

The deposition on the floor was always a bit higher for $10 \mu \mathrm{m}$ particles than for the others. The highest value $14 \%$ was in the case of incoming ventilation air preheated to $20^{\circ} \mathrm{C}$ otherwise the values reached around 5\%. In [7] it is shown the deposition loss rate coefficient as the function of particle size and the velocity of the air. In our case it is not yet possible to discuss the deposition with air speed, as the simulation was run in steady state. We can only see the influence of airspeed on the aerosol dispersion. The movement of particles in ventilated areas is strongly influenced by airflow pattern [8]. Velocities of the air are mainly a response to the movement of ventilation air or movement caused by buoyancy 
over heated surfaces. We can also see the influence of the interaction between the convective flows and behaviour of ventilation air on aerosol. That is why the deposition of $1 \mu \mathrm{m}$ and $2.5 \mu \mathrm{m}$ particles in the outlet reached $25 \%$ in the case when the temperature of ventilation air was not the highest but only $10^{\circ} \mathrm{C}$. The conclusion related to the incoming air, which governed the case of floor and ceiling heating did not seem to work for the case where more sources of momentum are presented. The deposition in the outlet decreased to only $6 \%$ when the temperature of incoming air raised to $20^{\circ} \mathrm{C}$. The deposition on the wall and the area where the inlet was situated belonged to the most affected area as usual. The deposition of $10 \mu \mathrm{m}$ particles is higher in the area of inlet opposite to a slightly higher deposition of fine particles on the wall around the inlet. The deposition on the radiators themselves was around $7 \%$ in the case when the heat flux was the lowest. The deposition on the ceiling was nearly always higher than the deposition on the floor except for the following case. It was proved that the effect of buoyancy on $10 \mu \mathrm{m}$ particles was not so significant when the radiator heating is at the lowest simulated value. There were two times more of these particles settled on the floor (14\%) than on the ceiling (7\%).

The deposition data were also divided and compared in order to take into account the area of the room where the aerosol source was situated and the area where not. The result was that the deposition took place mainly in the area where the inlet was situated. This is shown on the ceiling heating when the deposition on the area of inlet window and on the floor underneath makes more than $90 \%$ of all settled particles. The most of values in the area without source did not reach even $1 \%$ of deposited particles. In one case the deposition reached $9 \%$ for $1 \mu \mathrm{m}$ and $2.5 \mu \mathrm{m}$ particles in the case of radiator heating and adjusted temperature of ventilation air at $3.6^{\circ} \mathrm{C}$. In this case the deposition on the ceiling was uniform for the whole area concerned. Figure 3 shows the deposition on several surfaces for the conditions where the ventilation air is preheated nearly to the indoor temperature while outside temperature was reaching the wintertime average.

\section{Conclusions}

The highest contamination of the air by the dispersed aerosol was shown for the case of radiator heating. Convective flows caused by high temperature of radiator panels make the airflow in the room the most intensive. Thus the particles are dispersed most into several areas of the room. That caused the significant deposition on the ceiling for the case of radiator heating.

A different dispersion and deposition can be reached by suitable combination of ventilation air and the convective flows produced by radiators. It is shown that the least contamination of the air is only in the case of ceiling heating. Slightly different thermal conditions were reached by the floor heating, but aerosol dispersed more into the air than in the case of ceiling heating.

While the source of aerosol is the ventilation air, the most affected are the surfaces in the main field of its flow if there were no other sources of fluxes causing the vorticity of the air and the connected dispersion of aerosol. The warmer the air is the more straight direction it has and does not fall to the floor 

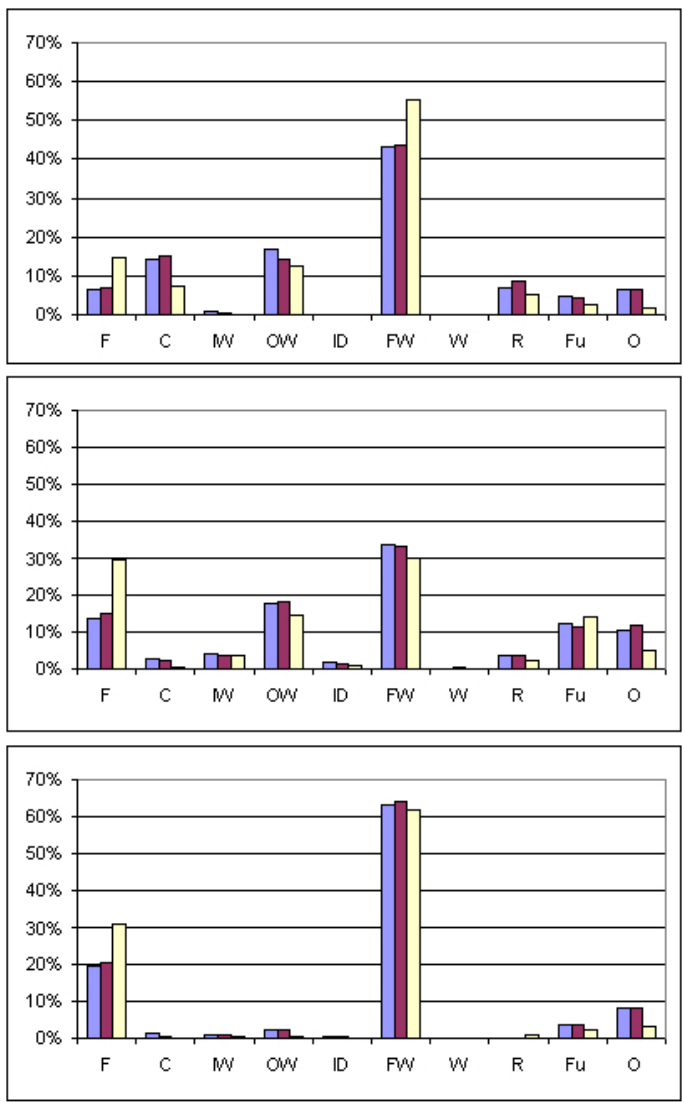

Figure 3: $\quad$ Relative deposition on several surfaces for the case of $t_{\text {out }}=3.6^{\circ} \mathrm{C}$, $\mathrm{t}_{\text {vent }}=20^{\circ} \mathrm{C}$, in order: radiator (up), floor, ceiling (down) heating system. Values of three particle sizes $1 \mu \mathrm{m}$ (blue/light grey), $2.5 \mu \mathrm{m}$ (red/dark grey) and $10 \mu \mathrm{m}$ (yellow/white) and surfaces in order from left to right: floor, ceiling, wall to indoor, wall to outdoor, indoor door, French window, window, radiators, furniture and outlets. F-floor, C-ceiling, IW-inner wall, OW-outer wall, IDinner door, FW-French windows, W-window, R-radiator, Fufurniture, O-outlet.

right after the inlet and therefore the dispersion of aerosol is higher too. Ventilating with the colder air can be the way of how to lower the dispersion of the aerosol coming from the outdoor air into the room. In general the effect of flow and buoyancy we can see on $1 \mu \mathrm{m}$ and $2.5 \mu \mathrm{m}$ particles. The deposition on the floor was typical of $10 \mu \mathrm{m}$ particles resulting mainly from the gravitational settling. The sense of deposition on the floor is considerable while the dust on 
floor surfaces is available for re-suspension of particles, dermal contact and ingestion through hand-to-mouth transfer [6].

Mostly the smaller particles of $1 \mu \mathrm{m}$ and $2.5 \mu \mathrm{m}$ reached the outlet in larger amount in case the incoming ventilation air was heated to a higher value. The particles which deposited there left the room. So if there is no negative influence on another part of the house, we can state that the depositing in the outlet area belongs to the positive aspects of lowering the concentrations of aerosol in the indoor air. The outlets had the highest values of mass flux per surface area. Finding a similar place with high mass surface flux located in high deposition zone could be a good solution for where to locate the air cleaner. On the other hand, we could find the best place where to position a bed or an artwork to protect it from damage. It is necessary to choose the right place for mounting the ventilation holes not to negatively affect the inhabited area. The energy needs to heat the room is constantly increasing. So it is necessary to find a compromise between dustiness, needs of energy and final comfort when assuring the desired indoor climate.

\section{Acknowledgement}

Financial support from the grant COST P20, number OC166 of the Czech Ministry of education, youth and sports is gratefully acknowledged.

\section{References}

[1] Abadie M., Limam K., and Allard F. (2001). Indoor particle pollution: Effect of wall textures on particle deposition. Building and Environment, 36:821-827.

[2] Abt E., Suh H. H., Allen G., and Koutrakis P. (2000). Characterization of indoor particle sources: A study conducted in the metropolitan Boston area. Environmental Health Perspectives, 108(1):35-44.

[3] Holmberg S. and Li Y. (1998). Modelling of the indoor environment particle dispersion and deposition. Indoor Air, 8:113-122.

[4] Jones A. P. (1999). Indoor air quality and health. Atmospheric Environment, $33: 4535-4564$.

[5] Morawska L., He C., Hitchins J., Gilbert D., and Parappukkaran S. (2001). The relationship between indoor and outdoor airborne particles in the residential environment. Atmospheric Environment, 35:3463-3473.

[6] Thatcher T. L., Layton D. W., (1995). Deposition, resuspension and penetration of particles within a residence. Atmospheric Environment, 29:1487-1497.

[7] Thatcher T. L., Lai A. C. K., Moreno-Jackson R., Sextro R.G., Nazaroff W. W. (2002). Effects of room furnishing and air speed on particle deposition rates indoors. Atmospheric environment, 36:1811-1819.

[8] Zhao B., Zhang Y., Li X., Yang X., and Huang, D. (2004). Comparison of indoor aerosol particle concentration and deposition in different ventilated rooms by numerical method. Building and Environment, 39:1-8. 